\title{
A Influência da Espiritualidade e da Religiosidade na Aceitação da Doença e no Tratamento de Pacientes Oncológicos: Revisão Integrativa da Literatura
}

doi: https://doi.org/10.32635/2176-9745.RBC.2020v66n2.422

\author{
The Influence of Spirituality and Religiosity in Acceptance of the Disease and Treatment of Oncologic Patients: an Integrative \\ Literature Review \\ La Influencia de la Espiritualidad y la Religiosidad en la Aceptación de Enfermedad y Tratamiento de Pacientes con Cáncer: \\ una Revisión Integradora de Literatura
}

Laura Fernandes Ferreira'; Alyssa de Pinho Freire ${ }^{2}$; Ana Luiza Cunha Silveira ${ }^{3}$; Anthony Pereira Martins Silva ${ }^{4}$; Hermon Corrêa de Sá5; Igor Soares Souza ${ }^{6}$; Lohane Stefany Araújo Garcia”; Rafael Silva Peralta ${ }^{8}$; Laís Moreira Borges Araujo ${ }^{9}$

Resumo

Introdução: A religiosidade e a espiritualidade são fatores ímpares na saúde do ser humano. Elas servem de auxílio para lidar com o câncer em seu processo de história natural. Objetivo: Analisar a produção científica nacional e internacional, acerca dos temas espiritualidade, religiosidade e pacientes oncológicos. Método: Revisão integrativa de literatura sobre a influência da espiritualidade e da religiosidade em pacientes oncológicos, nas bases de dados SciELO, MEDLINE e EBSCO e nos idiomas português e inglês, que buscou artigos publicados entre janeiro de 2009 e janeiro de 2019. Resultados: Oito artigos relataram a influência da religiosidade e da espiritualidade desde o momento do diagnóstico do câncer até a aceitaçáo do tratamento. Dez artigos relataram que ambas servem como apoio, chance de encarar a vida e a morte de forma diferentes e de melhorar a qualidade de vida e bem-estar do paciente. A religiosidade e a espiritualidade ajudam os pacientes com as consequências do câncer e influenciarão a sua vida e o seu modo de viver durante o tratamento. Além disso, constituem uma estratégia que legitima e ameniza a incerteza diante das questóes de caráter moral, pessoal e social, relativas à condição oncológica crônica. Conclusáo: $\mathrm{O}$ apego à espiritualidade e à religiosidade influencia positivamente na saúde biopsicossocial do paciente com câncer. Ademais, pacientes dotados de espiritualidade e religiosidade podem apresentar melhor maior aceitação do câncer do tratamento, além de maior esperança e positividade no decorrer da doença.

Palavras-chave: Espiritualidade; Religião e Medicina; Oncologia; Revisão.

\begin{abstract}
Introduction: Religiosity and spirituality are unique factors in human health. They are helpful in dealing with cancer in its natural course. Objective: Analyze the national and international scientific publications involving the themes of Spirituality and Religiosity in Cancer Patients. Method: Integrative literature review that searched SciELO, MEDLINE and EBSCO databases for articles published between January 2009 and January 2019, in Portuguese and in English, about the influence of spirituality and religiosity in cancer patients. Results: Eight articles reported the influence of religiosity and spirituality from the moment of cancer diagnosis through acceptance of the treatment. 10 articles reported that both serve as support, chance of facing life and death differently and to improve the patient's quality of life and well-being. Religiosity and spirituality help patients with the consequences of cancer and will influence their life and lifestyle during and after treatment. Moreover, they constitute a strategy that legitimizes and mitigates uncertainty about moral, personal and social issues related to the chronic oncological condition. Conclusion: Attachment to spirituality and religiosity positively influences the biopsychosocial health of cancer patients. Moreover, patients endowed with spirituality and religiosity may have better acceptance of cancer treatment, in addition of greater hope and positiveness during the course of the disease.

Key words: Spirituality; Religion and Medicine; Medical Oncology; Review.
\end{abstract}

Resumen

Introducción: La religiosidad y la espiritualidad son factores únicos en la salud humana. Son útiles para tratar el cáncer en su proceso de historia natural. Objetivo: Analizar la producción científica nacional e internacional, sobre los temas Espiritualidad, Religiosidad y Pacientes con cáncer. Método: Revisión bibliográfica integradora sobre la influencia de la espiritualidad y la religión en pacientes con cáncer en las bases de datos SciELO, MEDLINE y EBSCO, en idiomas portugués e inglés, quienes buscaron artículos publicados entre enero de 2009 y enero de 2019. Resultados: Ocho de los artículos informaron la influencia de la religiosidad y la espiritualidad desde el momento del diagnóstico del cáncer hasta la aceptación del tratamiento. Diez artigos informaron que ambos sirven como apoyo, una oportunidad para enfrentar la vida y la muerte de manera diferente y para mejorar la calidad de vida y el bienestar del paciente. La religiosidad y la espiritualidad ayudan a los pacientes con las consecuencias del cáncer e influirán en su vida y estilo de vida durante el tratamiento. Además, constituyen una estrategia que legitima y mitiga la incertidumbre frente a cuestiones morales, personales y sociales relacionadas con la condición oncológica crónica. Conclusion: Attachment to spirituality and religiosity positively influences the biopsychosocial health of cancer patients. Moreover, patients with spirituality and religiosity may have better acceptance of cancer treatment, and greater hope and positivity during the course of the disease.

Palabras clave: Espiritualidad; Religión y Medicina; Oncología Médica; Revisión.

\footnotetext{
${ }^{1}$ Curso de Medicina do Centro Universitário de Patos de Minas (Unipam). Patos de Minas (MG), Brasil. Orcid iD: https://orcid.org/0000-0001-8327-0724

${ }^{2}$ Curso de Medicina do Unipam. Patos de Minas (MG), Brasil. Orcid iD: https://orcid.org/0000-0001-8109-0367

${ }^{3}$ Curso de Medicina do Unipam. Patos de Minas (MG), Brasil. Orcid iD: https://orcid.org/0000-0002-9988-9043

${ }^{4}$ Curso de Medicina do Unipam. Patos de Minas (MG), Brasil. Orcid iD: https://orcid.org/0000-0003-0429-3341

${ }^{5}$ Curso de Medicina do Unipam. Patos de Minas (MG), Brasil. Orcid iD: https://orcid.org/0000-0002-4041-676X

${ }^{6}$ Curso de Medicina do Unipam. Patos de Minas (MG), Brasil. Orcid iD: https://orcid.org/0000-0002-4033-7551

${ }^{7}$ Curso de Medicina do Unipam. Patos de Minas (MG), Brasil. Orcid iD: https://orcid.org/0000-0002-3309-9639

${ }^{8}$ Curso de Medicina do Unipam. Patos de Minas (MG), Brasil. Orcid iD: https://orcid.org/0000-0001-6170-830X

${ }^{9}$ Docente do Unipam. Patos de Minas (MG), Brasil. Orcid iD: https://orcid.org/0000-0002-7027-5937

Endereço para correspondência: Laura Fernandes Ferreira. Rua Major Gote, 661, apto. 405 - Caiçaras. Patos de Minas (MG), Brasil. CEP 38700-107. E-mail: laurafernandes130@yahoo.com.br
} 


\section{INTRODUÇÃO}

A espiritualidade está relacionada ao sentimento de transcendência, elevação, sublimidade, atividade religiosa ou mística, já a religiosidade envolve a tendência natural para sentimentos religiosos e coisas sagradas ${ }^{1}$. Ambas são fatores ímpares para a promoção, prevenção e recuperação da saúde. Elas têm influência na melhora da qualidade de vida, a ponto de reduzir a utilização dos serviços de saúde e contribuir para manutenção de um estilo de vida saudável dos indivíduos mais comprometidos ${ }^{2}$.

Conforme relatos, a espiritualidade tem sua essência anterior ao cristianismo, mesmo se entendida como uma confissão explícita da vivência de uma determinada fé, estruturada em uma série de ritos e orquestrada em um modo de vida concreto. Os pitagóricos, seis séculos antes de Cristo, e os vedas, os bramanistas, os hinduístas e os xintoístas, três mil anos antes de Cristo, já lidavam com a espiritualidade, apesar de não a intitularem dessa forma ${ }^{3}$.

No contexto do câncer, que é um conjunto de mais de 100 doenças que têm em comum o crescimento desordenado de células, que invadem tecidos e órgãos ${ }^{4}$, pode-se verificar que o estigma social, a associação com a morte, o diagnóstico e o tratamento geram medo nos indivíduos e podem remeter a sofrimento, dor, preocupação com a autoimagem e a perda do atrativo sexual, da capacidade produtiva e do peso corporal'5.

A espiritualidade e a religiosidade podem servir de auxílio para lidar com o câncer, em seu processo de história natural. Estudos mostram que ambas influenciam positivamente na qualidade de vida do paciente com câncer ${ }^{5}$. Elas podem aparecer após o diagnóstico da doença, quando há a falta de sentido para a vida, o que faz com que o paciente busque algo para torná-la humanamente significativa; ou podem estar presentes desde antes do diagnóstico, com grandes influências na vida e cultura dos indivíduos, e serem fonte de força e esperança durante o diagnóstico e tratamento ${ }^{6}$.

A religiosidade e a espiritualidade, apesar de envolverem aspectos diferentes, podem complementar$-\mathrm{se}^{7}$. No Brasil, 94\% das pessoas se dizem religiosas, tornando-o o segundo país mais religioso do mundo, um número significativo para se buscar compreender como essa religiosidade afeta as pessoas, particularmente os pacientes oncológicos ${ }^{8}$.

Diante do exposto e com o propósito de aprofundar no conteúdo acerca da influência da espiritualidade e religiosidade em pacientes oncológicos, o presente estudo teve como objetivo analisar a produção científica nacional e internacional, acerca dos temas espiritualidade, religiosidade e pacientes oncológicos.

\section{MÉTODO}

O presente estudo consiste em uma revisão integrativa de literatura sobre a influência da espiritualidade e religiosidade na aceitação da doença e no tratamento de pacientes oncológicos. Para realizar a revisão, foram adotados passos, como definiçáo do tema, elaboração da questão de pesquisa, estabelecimento de critérios de busca na literatura, definição das informaçóes extraídas dos artigos, análise e interpretação dos resultados, identificação dos temas e núcleos de sentidos, e síntese da discussão do tema confrontando-o com a literatura estudada.

O estudo foi guiado pelas seguintes perguntas norteadoras: "De que forma o apego à espiritualidade/ religiosidade influencia na cura do câncer? Quais as diferenças no decorrer da doença entre pacientes com e sem apoio espiritual e religioso?”. Foram selecionados artigos dos bancos de dados da Scientific Electronic Library Online (SciELO), Medical Literature Analysis and Retrieval System Online (MEDLINE) e EBSCO Information Services. A busca foi realizada com base no Medical Subject Headings (MeSH) e nos Descritores em Ciências da Saúde (DeCS), tendo os seguintes descritores: "câncer" or "neoplasias" and "espiritualidade" or "religiosidade".

Essa seleção foi realizada entre os meses de fevereiro a junho de 2019, independentemente, por todos os pesquisadores da pesquisa que posteriormente se encontraram para comparar a amostragem selecionada, discutir as discrepâncias e chegar a um consenso acerca dos artigos incluídos no estudo. Para isso, foi construído um quadro com os resultados, que continha título, ano de publicação, tipo de artigo, idioma publicado e palavras-chave.

Como critérios de inclusão, foram considerados artigos originais, revisóes de literatura e relatos de casos que abordassem os temas espiritualidade, religiosidade e pacientes oncológicos, e que permitissem acesso integral ao conteúdo do estudo, publicados nos idiomas português ou inglês, entre janeiro de 2009 a janeiro de 2019. Foram excluídos do estudo, artigos que não abordaram, em conjunto, os temas espiritualidade e/ou religiosidade em pacientes oncológicos, artigos que abordaram aspectos da espiritualidade e/ou religiosidade em outras doenças, que não o câncer, e artigos duplicados nas bases de dados.

\section{RESULTADOS}

No total, foram encontrados 200 artigos e lidos os títulos e resumos publicados. Após leitura criteriosa das publicaçôes, 163 artigos náo foram utilizados por causa dos critérios de exclusão. Dessa forma, 37 artigos foram utilizados e analisados no presente estudo (Figura 1). 


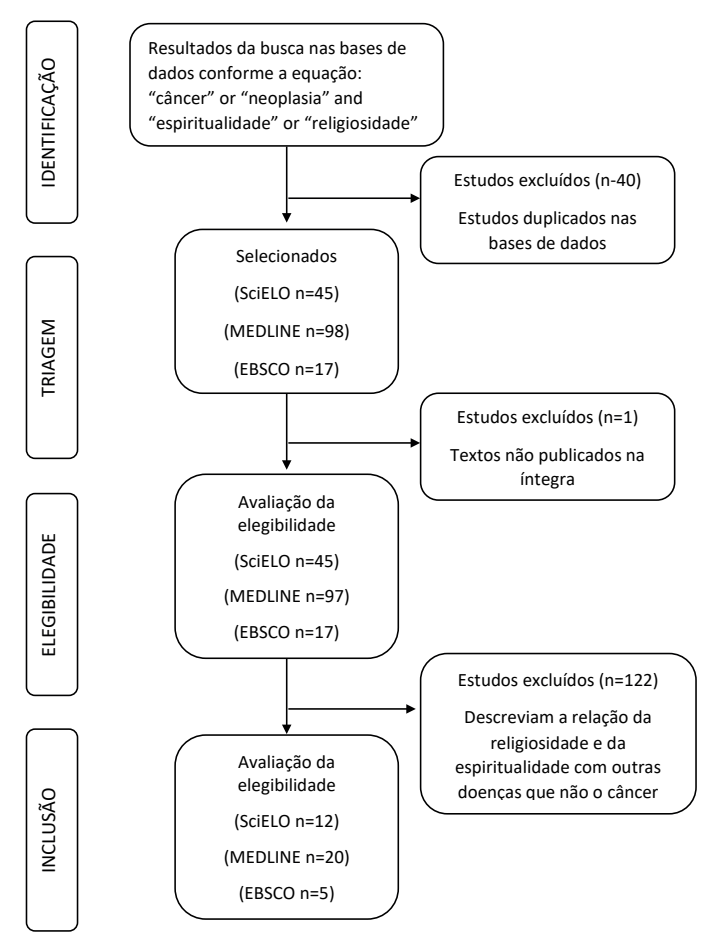

Figura 1. Fluxograma de seleção dos estudos. Patos de Minas, MG, Brasil, 2019

O Quadro 1 apresenta as evidências expressas nos artigos incluídos nesta revisão integrativa.

\section{DISCUSSÃO}

A espiritualidade é um fenômeno que se interconecta com raízes e cultura tradicionais, funde o corpo e a mente, e dá significado, força e fé na jornada do câncer?. O desenvolvimento espiritual tem sua importância já que faz parte de uma dimensão irredutível de toda pessoa, independentemente de sua identificação espiritual, cultural, religiosa ou outra ${ }^{10}$.

Vários estudos brasileiros e estadunidenses mostraram que a espiritualidade e a religiosidade contribuem para os pacientes enfrentarem o sofrimento de enfermidades como o câncer ${ }^{8,11-23}$. Mesmo com a doença em estágios mais avançados, a religiosidade e a espiritualidade podem desempenhar papéis importantes e inter-relacionados ${ }^{24}$.

Um estudo, feito por meio de entrevistas com pacientes oncológicos, em 2010, evidenciou que o enfrentamento religioso é uma estratégia de redução do estresse e melhoria da qualidade de vida das participantes ${ }^{23}$. Uma revisão de literatura e uma pesquisa com enfermeiros relacionaram a importância da espiritualidade e religiosidade para a redução apenas do estresse gerado pelo tratamento ${ }^{14,25}$.

Foi encontrada na literatura estadunidense, de 2018, uma correlação estatisticamente significativa entre saúde, bem-estar, felicidade e espiritualidade, influenciando o

Quadro 1. Espiritualidade e religiosidade em pacientes oncológicos

\begin{tabular}{|c|c|c|c|}
\hline Autor/Ano & Método & Objetivos & Principais achados \\
\hline $\begin{array}{l}\text { Puchalski et al., } \\
2019\end{array}$ & $\begin{array}{l}\text { Revisão de literatura } \\
\text { realizada com } 106 \\
\text { artigos }\end{array}$ & $\begin{array}{l}\text { Compreender a importância } \\
\text { da espiritualidade e das } \\
\text { intervenções baseadas } \\
\text { na espiritualidade no } \\
\text { cuidado oncológico; como } \\
\text { o cuidado espiritual pode } \\
\text { ser implementado no } \\
\text { tratamento oncológico e } \\
\text { fornecer recomendações } \\
\text { para a integração do cuidado } \\
\text { espiritual na oncologia }\end{array}$ & $\begin{array}{l}\text { Espiritualidade e bem-estar } \\
\text { espiritual têm provado um } \\
\text { efeito positivo em pacientes com } \\
\text { câncer, como um importante } \\
\text { componente de saúde e bem- } \\
\text {-estar geral }\end{array}$ \\
\hline $\begin{array}{l}\text { Moosavi et al., } \\
2019\end{array}$ & $\begin{array}{l}\text { Pesquisa qualitativa } \\
\text { realizada por meio } \\
\text { de entrevistas } \\
\text { semiestruturadas em } \\
\text { profundidade nos } \\
18 \text { participantes, } \\
\text { utilizando análise } \\
\text { de conteúdo } \\
\text { convencional, nos } \\
\text { Estado Unidos }\end{array}$ & $\begin{array}{l}\text { Explorar as consequências } \\
\text { do cuidado espiritual para } \\
\text { pacientes com câncer e } \\
\text { enfermeiros oncológicos na } \\
\text { perspectiva dos pacientes, } \\
\text { familiares, enfermeiros e outros } \\
\text { membros da equipe de saúde }\end{array}$ & $\begin{array}{l}\text { O cuidado espiritual coloca } \\
\text { o paciente com câncer e a } \\
\text { enfermeira oncológica no } \\
\text { caminho para o crescimento } \\
\text { espiritual. A conquista da paz } \\
\text { pelo paciente e pelo enfermeiro } \\
\text { é uma consequência comum do } \\
\text { cuidado espiritual que auxilia na } \\
\text { promoção do conforto, dá uma } \\
\text { sensação de paz ao paciente } \\
\text { e uma satisfação interior que } \\
\text { auxiliam no tratamento de } \\
\text { doenças }\end{array}$ \\
\hline
\end{tabular}


Quadro 1. continuação

\begin{tabular}{|c|c|c|c|}
\hline Autor/Ano & Método & Objetivos & Principais achados \\
\hline $\begin{array}{l}\text { Meneguin et al., } \\
2018\end{array}$ & $\begin{array}{l}\text { Pesquisa quantitativa, } \\
\text { por meio de } \\
\text { entrevistas, com } 96 \\
\text { pacientes oncológicos } \\
\text { em cuidados paliativos } \\
\text { no Brasil }\end{array}$ & $\begin{array}{l}\text { Entender a percepção de } \\
\text { pacientes com câncer em } \\
\text { cuidados paliativos sobre } \\
\text { qualidade de vida e identificar } \\
\text { proposições para o seu } \\
\text { aprimoramento }\end{array}$ & $\begin{array}{l}\text { A qualidade de vida está } \\
\text { ligada a significados de } \\
\text { saúde, bem-estar, felicidade e } \\
\text { espiritualidade, influenciando } \\
\text { repercussões do processo saúde- } \\
\text {-doença }\end{array}$ \\
\hline Silva et al., 2018 & $\begin{array}{l}\text { Pesquisa qualitativa, } \\
\text { entrevista com } 21 \\
\text { profissionais de saúde, } \\
\text { organizados em } \\
\text { enfermeiros; técnicos } \\
\text { de enfermagem; e } \\
\text { profissionais da equipe } \\
\text { multiprofissional de } \\
\text { saúde no Brasil }\end{array}$ & $\begin{array}{l}\text { Discutir as estratégias de ação } \\
\text { e interação adotadas pelos } \\
\text { profissionais de saúde para o } \\
\text { cuidado à criança hospitalizada } \\
\text { com dor oncológica crônica }\end{array}$ & $\begin{array}{l}\text { Busca da espiritualidade e do } \\
\text { equilíbrio emocional como } \\
\text { estratégias de ação necessárias } \\
\text { para lidar com o sofrimento } \\
\text { infantil e familiar }\end{array}$ \\
\hline $\begin{array}{l}\text { Gifford et al., } \\
2019 .\end{array}$ & $\begin{array}{l}\text { Pesquisa descritiva } \\
\text { qualitativa } \\
\text { realizada com } 31 \\
\text { sobreviventes do } \\
\text { câncer que discutiram } \\
\text { a espiritualidade } \\
\text { como parte de suas } \\
\text { experiências de } \\
\text { sobrevivência ao } \\
\text { câncer no Canadá }\end{array}$ & $\begin{array}{l}\text { Explorar os significados } \\
\text { da espiritualidade na } \\
\text { sobrevivência do câncer para } \\
\text { pessoas das Primeiras Nações, } \\
\text { maior população indígena } \\
\text { do Canadá, e descrever } \\
\text { como práticas espirituais são } \\
\text { incorporadas à cura }\end{array}$ & $\begin{array}{l}\text { A espiritualidade foi expressa } \\
\text { como um fenômeno que se } \\
\text { interconectou com raízes e } \\
\text { cultura tradicionais, fundiu } \\
\text { o corpo e a mente, e deu } \\
\text { significado, força e fé na jornada } \\
\text { do câncer }\end{array}$ \\
\hline Xing et al., 2018 & $\begin{array}{l}\text { Revisão de literatura } \\
\text { realizada com } 10 \\
\text { artigos }\end{array}$ & $\begin{array}{l}\text { Usar ensaios clínicos } \\
\text { randomizados para avaliar } \\
\text { os efeitos de intervenções } \\
\text { espirituais sobre os resultados } \\
\text { espirituais e psicológicos e } \\
\text { qualidade de vida em pacientes } \\
\text { com câncer }\end{array}$ & $\begin{array}{l}\text { Intervenções espirituais podem } \\
\text { melhorar o bem-estar espiritual } \\
\text { e a qualidade de vida e reduzir } \\
\text { a depressão, a ansiedade e } \\
\text { a falta de esperança para } \\
\text { pacientes com câncer }\end{array}$ \\
\hline $\begin{array}{l}\text { Visser et al., } \\
2018\end{array}$ & $\begin{array}{l}2 \text { estudos de } \\
\text { questionário - } 1 \\
\text { estudo transversal e } \\
1 \text { longitudinal de um } \\
\text { ano investigados entre } \\
\text { pacientes de câncer na } \\
\text { Holanda }\end{array}$ & $\begin{array}{l}\text { Identificar se a espiritualidade } \\
\text { diminui o impacto da dor, } \\
\text { fadiga, e ameaça de vida } \\
\text { percebida frente a perigos }\end{array}$ & $\begin{array}{l}\text { A espiritualidade reduz o } \\
\text { impacto da dor, fadiga ou } \\
\text { percepção de ameaça à } \\
\text { vida em situações de perigo. } \\
\text { Significância e aceitação podem } \\
\text { reduzir o impacto negativo do } \\
\text { aumento da fadiga durante } \\
\text { o primeiro ano após o início } \\
\text { do tratamento do câncer. A } \\
\text { espiritualidade pode aumentar o } \\
\text { impacto negativo da ameaça à } \\
\text { vida percebida }\end{array}$ \\
\hline $\begin{array}{l}\text { Oliveira et al., } \\
2018\end{array}$ & $\begin{array}{l}\text { Pesquisa quali- } \\
\text {-quantitativa, } \\
\text { descritiva, transversal, } \\
\text { realizada com } \\
101 \text { participantes } \\
\text { em tratamento de } \\
\text { quimioterapia no } \\
\text { Brasil }\end{array}$ & $\begin{array}{l}\text { Avaliar a influência da } \\
\text { espiritualidade, religiosidade e } \\
\text { crenças pessoais na qualidade } \\
\text { de vida de pacientes em } \\
\text { quimioterapia }\end{array}$ & $\begin{array}{l}\text { A fé em Deus é o que dá } \\
\text { condições de enfrentamento da } \\
\text { doença. É importante considerar } \\
\text { a magnitude da dimensão } \\
\text { espiritual para o paciente } \\
\text { oncológico no enfrentamento } \\
\text { da doença, o que pode } \\
\text { beneficiá-lo durante o tempo de } \\
\text { adoecimento e convalescença }\end{array}$ \\
\hline
\end{tabular}


Quadro 1. continuação

\begin{tabular}{|c|c|c|c|}
\hline Autor/Ano & Método & Objetivos & Principais achados \\
\hline $\begin{array}{l}\text { Sousa et al., } \\
2017\end{array}$ & $\begin{array}{l}\text { Revisão de literatura } \\
\text { realizada com } 11 \\
\text { artigos }\end{array}$ & $\begin{array}{l}\text { Identificar as evidências } \\
\text { científicas disponíveis sobre a } \\
\text { abordagem de enfrentamento } \\
\text { religioso/espiritual usado } \\
\text { por pessoas com câncer em } \\
\text { tratamento quimioterápico }\end{array}$ & $\begin{array}{l}\text { A religiosidade/espiritualidade } \\
\text { é uma estratégia de abordagem } \\
\text { positiva que contribui para } \\
\text { a adesão ao tratamento } \\
\text { quimioterápico e redução do } \\
\text { estresse. O efeito negativo foi } \\
\text { associado com a incidência de } \\
\text { efeitos colaterais, sofrimento } \\
\text { psicológico, ansiedade e } \\
\text { depressão }\end{array}$ \\
\hline $\begin{array}{l}\text { Freire et al., } \\
2017\end{array}$ & $\begin{array}{l}\text { Pesquisa exploratória, } \\
\text { com abordagem } \\
\text { qualitativa, realizada } \\
\text { com pacientes } \\
\text { acometidos por câncer } \\
\text { no Brasil }\end{array}$ & $\begin{array}{l}\text { Investigar como pacientes } \\
\text { com diagnóstico de câncer } \\
\text { concebem o apoio religioso/ } \\
\text { espiritual no contexto } \\
\text { hospitalar }\end{array}$ & $\begin{array}{l}\text { A religiosidade/espiritualidade } \\
\text { é uma importante tática } \\
\text { para enfrentar a doença } \\
\text { oncológica, considerando que } \\
\text { os entrevistados relataram o } \\
\text { significado positivo do apoio } \\
\text { recebido, porque a fé fornece } \\
\text { uma forma construtiva de } \\
\text { pensamento }\end{array}$ \\
\hline $\begin{array}{l}\text { Kiyancicek e } \\
\text { Caydam, } 2017\end{array}$ & $\begin{array}{l}\text { Pesquisa descritiva e } \\
\text { transversal, realizada } \\
\text { com } 230 \text { familiares } \\
\text { cuidadores da clínica } \\
\text { de hematologia } \\
\text { oncológica } \\
\text { hospitalizados e } \\
\text { ambulatoriais no Brasil }\end{array}$ & $\begin{array}{l}\text { Avaliar as necessidades e } \\
\text { as práticas espirituais entre } \\
\text { familiares cuidadores de } \\
\text { pacientes com câncer }\end{array}$ & $\begin{array}{l}\text { O processo de cuidado deve } \\
\text { ser planejado para fornecer } \\
\text { necessidades e práticas } \\
\text { espirituais entre os cuidadores } \\
\text { familiares de pacientes com } \\
\text { câncer }\end{array}$ \\
\hline $\begin{array}{l}\text { Caldeira et al., } \\
2017\end{array}$ & $\begin{array}{l}\text { Estudo transversal } \\
\text { usando o modelo } \\
\text { de validade de } \\
\text { diagnóstico clínico de } \\
\text { Richard Fehring }\end{array}$ & $\begin{array}{l}\text { Validar o diagnóstico de } \\
\text { enfermagem no sofrimento } \\
\text { espiritual em pacientes com } \\
\text { câncer }\end{array}$ & $\begin{array}{l}\text { Pacientes com câncer em } \\
\text { sofrimento espiritual estão } \\
\text { em um estado de sofrimento } \\
\text { relacionado à falta de } \\
\text { significado na vida }\end{array}$ \\
\hline $\begin{array}{l}\text { Sousa Junior et } \\
\text { al., } 2017\end{array}$ & $\begin{array}{l}\text { Revisão de literatura } \\
\text { realizada com } 25 \\
\text { artigos }\end{array}$ & $\begin{array}{l}\text { Analisar as discussões } \\
\text { científicas existentes sobre } \\
\text { como a espiritualidade auxilia } \\
\text { na adesão das pessoas com } \\
\text { câncer ao tratamento proposto } \\
\text { e como isso o fortalece diante } \\
\text { desse quadro de adoecimento }\end{array}$ & $\begin{array}{l}\text { A espiritualidade proporciona } \\
\text { uma ressignificação da } \\
\text { enfermidade para o sujeito, } \\
\text { fazendo-o encarar a doença de } \\
\text { outra forma. O sujeito passa } \\
\text { a ter novas metas e desafios } \\
\text { a cumprir e a espiritualidade } \\
\text { oferece o suporte necessário } \\
\text { para encarar essa etapa }\end{array}$ \\
\hline $\begin{array}{l}\text { Matos et al., } \\
2017\end{array}$ & $\begin{array}{l}\text { Estudo transversal } \\
\text { realizado com } \\
96 \text { pacientes de } \\
\text { ambulatório de } \\
\text { cuidados paliativos, } \\
\text { em um hospital } \\
\text { público no Brasil e } 96 \\
\text { voluntários saudáveis }\end{array}$ & $\begin{array}{l}\text { Comparar a qualidade de vida } \\
\text { e o coping religioso-espiritual } \\
\text { de pacientes em cuidados } \\
\text { paliativos oncológicos com um } \\
\text { grupo de participantes sadios }\end{array}$ & $\begin{array}{l}\text { Indivíduos com maiores } \\
\text { escores de coping espiritual- } \\
\text {-religioso apresentaram melhor } \\
\text { percepção de qualidade de vida, } \\
\text { sugerindo que essa estratégia } \\
\text { de enfrentamento possa ser } \\
\text { estimulada em pacientes sob } \\
\text { cuidados paliativos }\end{array}$ \\
\hline
\end{tabular}


Quadro 1. continuação

\begin{tabular}{|c|c|c|c|}
\hline Autor/Ano & Método & Objetivos & Principais achados \\
\hline $\begin{array}{l}\text { Benites et al., } \\
2017\end{array}$ & $\begin{array}{l}\text { Pesquisa qualitativa } \\
\text { de inspiração } \\
\text { fenomenológica, } \\
\text { na qual foram } \\
\text { identificadas, descritas } \\
\text { e analisadas as } \\
\text { vivências de pacientes } \\
\text { com câncer em } \\
\text { cuidados paliativos } \\
\text { e o significado da } \\
\text { espiritualidade para } \\
\text { esses indivíduos nesse } \\
\text { contexto específico no } \\
\text { Brasil }\end{array}$ & $\begin{array}{l}\text { Compreender as vivências } \\
\text { de pacientes com câncer } \\
\text { em cuidados paliativos e o } \\
\text { significado da espiritualidade } \\
\text { ante a dor do adoecimento e a } \\
\text { possibilidade de morte }\end{array}$ & $\begin{array}{l}\text { A dimensão espiritual é } \\
\text { importante na vivência } \\
\text { do processo de morrer, } \\
\text { possibilitando a busca de } \\
\text { sentidos para a vida e para a } \\
\text { morte. Estar ante a morte, leva } \\
\text { à veneração da vida, remetendo } \\
\text { às crenças pessoais e ao que } \\
\text { se busca como sentidos para o } \\
\text { viver }\end{array}$ \\
\hline $\begin{array}{l}\text { Nejat et al., } \\
2017\end{array}$ & $\begin{array}{l}\text { Pesquisa qualitativa } \\
\text { transversal com } \\
\text { entrevistas conduzidas } \\
\text { na Nova Zelândia e Irã }\end{array}$ & $\begin{array}{l}\text { Explorar e comparar o uso da } \\
\text { espiritualidade e religiosidade } \\
\text { no enfrentamento do câncer } \\
\text { colorretal na Nova Zelândia e } \\
\text { no Irã }\end{array}$ & $\begin{array}{l}\text { A maioria dos participantes } \\
\text { entrevistados utilizou a } \\
\text { religiosidade como recurso } \\
\text { no enfrentamento do câncer. } \\
\text { Crenças religiosas e/ou } \\
\text { espirituais formaram uma } \\
\text { importante fonte de apoio para } \\
\text { todos os entrevistados no Irã e } \\
\text { para a maioria dos entrevistados } \\
\text { na Nova Zelândia que vivem } \\
\text { com câncer }\end{array}$ \\
\hline $\begin{array}{l}\text { Sampaio e } \\
\text { Siqueira, } 2016\end{array}$ & $\begin{array}{l}\text { Pesquisa com } \\
10 \text { enfermeiros } \\
\text { assistenciais que } \\
\text { participam ativamente } \\
\text { nos cuidados de } \\
\text { enfermagem aos } \\
\text { usuários oncológicos } \\
\text { assistidos no Brasil }\end{array}$ & $\begin{array}{l}\text { Analisar a influência da } \\
\text { espiritualidade no tratamento } \\
\text { do usuário oncológico sob o } \\
\text { olhar do enfermeiro }\end{array}$ & $\begin{array}{l}\text { Buscar significação e conforto na } \\
\text { religiosidade ameniza o estresse } \\
\text { causado pela dor e pelas } \\
\text { mudanças acarretadas pela } \\
\text { doença e pela proximidade da } \\
\text { morte. O usuário pode transferir } \\
\text { sua responsabilidade para Deus } \\
\text { ou um "Ser Supremo", tornando } \\
\text { o fardo da doença suportável }\end{array}$ \\
\hline $\begin{array}{l}\text { Canassa e Ferret, } \\
2016\end{array}$ & $\begin{array}{l}\text { Revisão de literatura } \\
\text { realizada com } 13 \\
\text { artigos }\end{array}$ & $\begin{array}{l}\text { Perceber as principais questões } \\
\text { psicológicas e de saúde mental } \\
\text { em pacientes oncológicos, } \\
\text { que buscam refúgio religioso } \\
\text { e espiritual para dar sentido a } \\
\text { suas vidas }\end{array}$ & $\begin{array}{l}\text { A espiritualidade/religiosidade, } \\
\text { quando bem incorporada na } \\
\text { vida do paciente, o ajudará } \\
\text { com as consequências que essa } \\
\text { doença trará para seu dia a dia } \\
\text { e influenciará essencialmente a } \\
\text { sua vida e o seu modo de viver } \\
\text { durante o tratamento }\end{array}$ \\
\hline Jim et al., 2015 & $\begin{array}{l}\text { Revisão de literatura } \\
\text { realizada com } 101 \\
\text { artigos }\end{array}$ & $\begin{array}{l}\text { Associar a religião e a } \\
\text { espiritualidade de pacientes } \\
\text { com câncer a melhores } \\
\text { resultados de saúde física }\end{array}$ & $\begin{array}{l}\text { Maior religiosidade e } \\
\text { espiritualidade estão associadas } \\
\text { com uma melhor saúde física } \\
\text { geral, bem-estar físico e funcional } \\
\text { e com menores sintomas físicos } \\
\text { relatados pelo paciente }\end{array}$ \\
\hline $\begin{array}{l}\text { Hatamipour et } \\
\text { al., } 2015\end{array}$ & $\begin{array}{l}\text { Pesquisa com } \\
18 \text { pacientes } \\
\text { oncológicos com } \\
\text { necessidades } \\
\text { espirituais que } \\
\text { emergiram da } \\
\text { análise de conteúdo } \\
\text { convencional de } \\
\text { entrevistas conduzidas } \\
\text { com eles no Irã }\end{array}$ & $\begin{array}{l}\text { Explicar as necessidades } \\
\text { espirituais de pacientes com } \\
\text { câncer no Irã }\end{array}$ & $\begin{array}{l}\text { Pacientes entrevistados no Irã } \\
\text { buscam ajuda da espiritualidade } \\
\text { para aceitar ou lidar com } \\
\text { sua doença. As necessidades } \\
\text { espirituais dos pacientes com } \\
\text { câncer devem ser reconhecidas, } \\
\text { realizadas e consideradas no } \\
\text { cuidado dos pacientes pela } \\
\text { equipe médica }\end{array}$ \\
\hline
\end{tabular}


Quadro 1. continuação

\begin{tabular}{|c|c|c|c|}
\hline Autor/Ano & Método & Objetivos & Principais achados \\
\hline $\begin{array}{l}\text { Souza et al., } \\
2015\end{array}$ & $\begin{array}{l}\text { Pesquisa qualitativa, } \\
\text { descritiva e } \\
\text { exploratória, realizada } \\
\text { com nove adolescentes } \\
\text { sobre tratamento } \\
\text { oncológico em duas } \\
\text { instituições no Brasil }\end{array}$ & $\begin{array}{l}\text { Analisar a concepção dos } \\
\text { adolescentes a respeito da } \\
\text { espiritualidade, religião e } \\
\text { crenças pessoais presentes } \\
\text { em suas vidas em razão do } \\
\text { câncer e como estratégia de } \\
\text { enfrentamento da doença }\end{array}$ & $\begin{array}{l}\text { A espiritualidade é importante } \\
\text { no enfrentamento a doença, } \\
\text { especialmente a partir de } \\
\text { rituais religiosos e apoio da } \\
\text { comunidade, além de gerar } \\
\text { esperança para enfrentar as } \\
\text { suas dificuldades e proporcionar } \\
\text { um novo sentido à suas vidas }\end{array}$ \\
\hline Silva et al., 2015 & Relato de caso & $\begin{array}{l}\text { Demonstrar a integração da } \\
\text { dimensão espiritual ao binômio } \\
\text { saúde-doença }\end{array}$ & $\begin{array}{l}\text { Reconhecimento da dimensão } \\
\text { espiritual na avaliação } \\
\text { adequada da dor total. Destaca } \\
\text { a importância da assistência } \\
\text { espiritual para o controle da } \\
\text { dor, uma vez que todo estado } \\
\text { espiritual pode ter influência } \\
\text { direta na percepção da dor } \\
\text { como sofrimento }\end{array}$ \\
\hline $\begin{array}{l}\text { Miranda et al., } \\
2015\end{array}$ & $\begin{array}{l}\text { Pesquisa exploratória } \\
\text { com } 15 \text { participantes } \\
\text { diagnosticados com } \\
\text { câncer, no Brasil }\end{array}$ & $\begin{array}{l}\text { Investigar inter-relações entre } \\
\text { bem-estar espiritual, depressão } \\
\text { e qualidade de vida durante o } \\
\text { enfrentamento do câncer }\end{array}$ & $\begin{array}{l}\text { O câncer favorece a busca pela } \\
\text { espiritualidade/religiosidade } \\
\text { como mecanismos de } \\
\text { enfrentamento do sofrimento, } \\
\text { como fonte de esperança de } \\
\text { cura e como ressignificação do } \\
\text { sentido da vida e da morte }\end{array}$ \\
\hline $\begin{array}{l}\text { Balboni et al., } \\
2014\end{array}$ & $\begin{array}{l}\text { Revisão de literatura } \\
\text { realizada com } 41 \\
\text { artigos }\end{array}$ & $\begin{array}{l}\text { Distinguir o modelo de } \\
\text { atendimento integral; uma } \\
\text { visão que identifica um papel } \\
\text { para o clínico na promoção da } \\
\text { saúde plena e uma visão de } \\
\text { pluralismo aberto, que destaca } \\
\text { a importância de diferentes } \\
\text { tradições espirituais e culturais }\end{array}$ & $\begin{array}{l}\text { O desenvolvimento espiritual } \\
\text { é importante porque faz } \\
\text { parte de uma dimensão } \\
\text { irredutível de toda pessoa, } \\
\text { independentemente de sua } \\
\text { identificação espiritual, cultural, } \\
\text { religiosa ou outra }\end{array}$ \\
\hline $\begin{array}{l}\text { Carvalho et al., } \\
2014\end{array}$ & $\begin{array}{l}\text { Estudo quase } \\
\text { experimental com pré } \\
\text { e pós-intervenção, } \\
\text { entre } 20 \text { pacientes } \\
\text { internados em } \\
\text { tratamento de } \\
\text { quimioterapia } \\
\text { endovenosa contínua, } \\
\text { no Brasil }\end{array}$ & $\begin{array}{l}\text { Avaliar o efeito da prece sobre } \\
\text { a ansiedade de pacientes } \\
\text { com câncer em tratamento } \\
\text { quimioterápico }\end{array}$ & $\begin{array}{l}\text { A prece demonstrou ser uma } \\
\text { estratégia eficiente na redução } \\
\text { da ansiedade do paciente em } \\
\text { tratamento de quimioterapia }\end{array}$ \\
\hline $\begin{array}{l}\text { Gobatto e } \\
\text { Araújo, } 2013\end{array}$ & $\begin{array}{l}\text { Estudo descritivo e } \\
\text { exploratório, quanti- } \\
\text {-qualitativo, } \\
\text { organizado em duas } \\
\text { etapas, no Brasil }\end{array}$ & $\begin{array}{l}\text { Conhecer, analisar e } \\
\text { compreender as concepções } \\
\text { de profissionais da saúde } \\
\text { acerca da associação entre } \\
\text { religiosidade, espiritualidade e } \\
\text { saúde em oncologia }\end{array}$ & $\begin{array}{l}\text { Os participantes evidenciaram } \\
\text { concepções positivas sobre a } \\
\text { influência da religiosidade/ } \\
\text { espiritualidade para a saúde, } \\
\text { com efeitos negativos em menor } \\
\text { proporção }\end{array}$ \\
\hline $\begin{array}{l}\text { Mesquita et al., } \\
2013\end{array}$ & $\begin{array}{l}\text { Estudo quantitativo, } \\
\text { descritivo e transversal, } \\
\text { com } 101 \text { pacientes } \\
\text { em quimioterapia } \\
\text { endovenosa, em } \\
\text { ambulatório de } \\
\text { oncologia de hospital } \\
\text { público do Brasil }\end{array}$ & $\begin{array}{l}\text { Investigar o uso do } \\
\text { enfrentamento religioso/ } \\
\text { espiritual por pessoas com } \\
\text { câncer em quimioterapia }\end{array}$ & $\begin{array}{l}\text { O coping religioso/espiritual } \\
\text { é importante estratégia de } \\
\text { enfrentamento do câncer } \\
\text { e contribui para a sua } \\
\text { compreensão como ferramenta } \\
\text { útil para o cuidado espiritual }\end{array}$ \\
\hline
\end{tabular}


Quadro 1. continuação

\begin{tabular}{|c|c|c|c|}
\hline Autor/Ano & Método & Objetivos & Principais achados \\
\hline $\begin{array}{l}\text { Espinha e Lima, } \\
2012\end{array}$ & $\begin{array}{l}\text { Revisão de literatura } \\
\text { realizada com } 41 \\
\text { artigos }\end{array}$ & $\begin{array}{l}\text { Analisar a produção científica } \\
\text { relativa à dimensão espiritual } \\
\text { de crianças e adolescentes com } \\
\text { câncer }\end{array}$ & $\begin{array}{l}\text { As questões relacionadas à } \\
\text { espiritualidade podem refletir } \\
\text { como importantes estratégias } \\
\text { de enfrentamento durante a } \\
\text { doença, possibilitando a busca } \\
\text { de significado e propósito na } \\
\text { vida dos pacientes, além de } \\
\text { influenciar nas decisões médicas } \\
\text { e delinear os elementos da } \\
\text { experiência da doença, desde o } \\
\text { diagnóstico, sofrimento e morte }\end{array}$ \\
\hline $\begin{array}{l}\text { Guerrero et al., } \\
2011\end{array}$ & $\begin{array}{l}\text { Estudo qualitativo } \\
\text { com participação de } \\
14 \text { pacientes com } \\
\text { câncer em tratamento } \\
\text { quimioterápico e } \\
\text { analisado segundo a } \\
\text { análise de conteúdo } \\
\text { temática indutiva, no } \\
\text { Brasil }\end{array}$ & $\begin{array}{l}\text { Compreender a relação entre } \\
\text { espiritualidade e o câncer } \\
\text { na perspectiva de pacientes } \\
\text { oncológicos }\end{array}$ & $\begin{array}{l}\text { O paciente oncológico busca } \\
\text { a espiritualidade como forma } \\
\text { de enfrentamento da doença, } \\
\text { com a finalidade de minimizar } \\
\text { o sofrimento ou obter maior } \\
\text { esperança de cura com o } \\
\text { tratamento }\end{array}$ \\
\hline $\begin{array}{l}\text { Lucchetti et al., } \\
2010\end{array}$ & $\begin{array}{l}\text { Revisão de literatura } \\
\text { realizada com } 38 \\
\text { artigos }\end{array}$ & $\begin{array}{l}\text { Traçar um panorama do } \\
\text { uso da espiritualidade na } \\
\text { prática clínica e quais os } \\
\text { conhecimentos básicos } \\
\text { necessários para o clínico } \\
\text { abordá-la na sua prática diária }\end{array}$ & $\begin{array}{l}\text { Atividades e crenças religiosas } \\
\text { estão relacionadas à melhor } \\
\text { saúde e qualidade de vida. A } \\
\text { maioria dos pacientes gostaria } \\
\text { que seus médicos abordassem } \\
\text { sobre sua religiosidade e } \\
\text { espiritualidade e sentiriam mais } \\
\text { empatia e confiança no médico } \\
\text { que questionasse esses temas }\end{array}$ \\
\hline $\begin{array}{l}\text { Alcorn et al., } \\
2010\end{array}$ & $\begin{array}{l}\text { Pequisa multicêntrica, } \\
\text { transversal, de } \\
\text { métodos mistos, } \\
\text { com } 68 \text { pacientes } \\
\text { oncológicos } \\
\text { selecionados } \\
\text { aleatoriamente }\end{array}$ & $\begin{array}{l}\text { Derivar temas centrais de } \\
\text { religião e/ou espiritualidade } \\
\text { ativos em experiências } \\
\text { de pacientes com câncer } \\
\text { avançado para informar } \\
\text { o desenvolvimento de } \\
\text { intervenções de cuidado } \\
\text { espiritual no cenário de câncer } \\
\text { em estado terminal }\end{array}$ & $\begin{array}{l}\text { Religiosidade e/ou } \\
\text { espiritualidade desempenham } \\
\text { vários papéis importantes e } \\
\text { inter-relacionados para os } \\
\text { pacientes com câncer mais } \\
\text { avançados }\end{array}$ \\
\hline $\begin{array}{l}\text { Pinto e Ribeiro, } \\
2010\end{array}$ & $\begin{array}{l}\text { Participaram nesse } \\
\text { estudo } 426 \text { pessoas } \\
\text { que tinham tido uma } \\
\text { doença oncológica }\end{array}$ & $\begin{array}{l}\text { Analisar as diferenças da } \\
\text { espiritualidade de acordo com } \\
\text { as variáveis sociodemográficas } \\
\text { e clínicas; avaliar a correlação } \\
\text { entre as dimensões da } \\
\text { espiritualidade e a qualidade } \\
\text { de vida }\end{array}$ & $\begin{array}{l}\text { Verificou-se um valor moderado, } \\
\text { embora significativo entre a } \\
\text { espiritualidade e a qualidade de } \\
\text { vida. Os resultados reforçam a } \\
\text { relevância de uma perspectiva } \\
\text { integral do sujeito, quando } \\
\text { objeto de cuidados de saúde }\end{array}$ \\
\hline $\begin{array}{l}\text { Espíndula et al., } \\
2010\end{array}$ & $\begin{array}{l}\text { Pesquisa qualitativa, } \\
\text { descritiva sob o } \\
\text { referencial de análise } \\
\text { fenomenológica em } \\
\text { Stein e Ales Bello. Um } \\
\text { modo de compreender } \\
\text { o ser humano na sua } \\
\text { totalidade - física, } \\
\text { psíquica e espiritual }\end{array}$ & $\begin{array}{l}\text { Compreender como } \\
\text { profissionais de saúde } \\
\text { significam religiosidade } \\
\text { e fé dos pacientes em } \\
\text { tratamento de câncer, e como } \\
\text { experienciam esse fenômeno }\end{array}$ & $\begin{array}{l}\text { Os convictos de suas religiões } \\
\text { creem na proteção divina e } \\
\text { reconhecem a religiosidade } \\
\text { como sustento e conforto para } \\
\text { o paciente e seus familiares } \\
\text { enfrentarem a situação de } \\
\text { adoecimento. Eles esperam } \\
\text { que esses enfermos vivam a } \\
\text { sua fé com prudência e sempre } \\
\text { aderindo à realidade }\end{array}$ \\
\hline
\end{tabular}


Quadro 1. continuação

\begin{tabular}{|c|c|c|c|}
\hline Autor/Ano & Método & Objetivos & Principais achados \\
\hline $\begin{array}{l}\text { Fornazari e } \\
\text { Ferreira, } 2010\end{array}$ & $\begin{array}{l}\text { Entrevistas com } 10 \\
\text { pacientes oncológicos } \\
\text { de uma instituição } \\
\text { especializada, no } \\
\text { Brasil }\end{array}$ & $\begin{array}{l}\text { Investigar o enfrentamento } \\
\text { religioso em pacientes } \\
\text { oncológicos }\end{array}$ & $\begin{array}{l}\text { Todas as participantes } \\
\text { apresentaram relatos verbais } \\
\text { com conteúdos de religiosidade/ } \\
\text { espiritualidade, o que evidencia } \\
\text { que a relação entre a doença } \\
\text { e a possibilidade de morte } \\
\text { fazem do enfrentamento } \\
\text { religioso uma estratégia de } \\
\text { redução do estresse e melhoria } \\
\text { da qualidade de vida das } \\
\text { participantes }\end{array}$ \\
\hline $\begin{array}{l}\text { Nascimento et } \\
\text { al., } 2010\end{array}$ & $\begin{array}{l}\text { Revisão de literatura } \\
\text { realizada com } 20 \\
\text { artigos }\end{array}$ & $\begin{array}{l}\text { Abordar o cuidado espiritual } \\
\text { oferecido pela enfermagem, } \\
\text { como parte dos pressupostos } \\
\text { para a promoção da saúde de } \\
\text { famílias que possuem crianças } \\
\text { e adolescentes com câncer }\end{array}$ & $\begin{array}{l}\text { A religiosidade e a } \\
\text { espiritualidade são fontes de } \\
\text { conforto e esperança e têm } \\
\text { auxiliado na melhor aceitação } \\
\text { da condição crônica da criança e } \\
\text { do adolescente }\end{array}$ \\
\hline $\begin{array}{l}\text { Spadacio e } \\
\text { Barros, } 2009\end{array}$ & $\begin{array}{l}\text { Pesquisa qualitativa } \\
\text { que, com uma } \\
\text { pequena população } \\
\text { selecionada, busca } \\
\text { aprofundar a } \\
\text { experiência do uso de } \\
\text { medicinas alternativas } \\
\text { e complementares } \\
\text { no tratamento do } \\
\text { câncer, contribuindo } \\
\text { para o debate sobre } \\
\text { a importância das } \\
\text { práticas religiosas e } \\
\text { da espiritualidade no } \\
\text { campo da saúde do } \\
\text { Brasil }\end{array}$ & $\begin{array}{l}\text { Refletir sobre interfaces que } \\
\text { auxiliam na reflexão teórica e } \\
\text { metodológica da existência de } \\
\text { práticas religiosas nos serviços } \\
\text { de saúde, como processos de } \\
\text { negociação dos sujeitos frente } \\
\text { a um evento de doença crônica }\end{array}$ & $\begin{array}{l}\text { A prática religiosa vivenciada } \\
\text { pelos pacientes constitui-se } \\
\text { como estratégia que legitima } \\
\text { e ameniza a incerteza diante } \\
\text { das questões de caráter moral, } \\
\text { pessoal, social e, também, físico, } \\
\text { relativas à condição oncológica } \\
\text { crônica }\end{array}$ \\
\hline $\begin{array}{l}\text { Tarouco et al., } \\
2009 .\end{array}$ & $\begin{array}{l}\text { Pesquisa exploratória } \\
\text { descritiva, de } \\
\text { abordagem qualitativa, } \\
\text { com } 5 \text { pacientes em } \\
\text { tratamento paliativo } \\
\text { pelo programa de } \\
\text { internação domiciliar } \\
\text { oncológico, no Brasil }\end{array}$ & $\begin{array}{l}\text { Identificar se a espiritualidade } \\
\text { ajuda os pacientes oncológicos } \\
\text { em sua fase terminal }\end{array}$ & $\begin{array}{l}\text { A busca pela espiritualidade na } \\
\text { condição terminal é uma forma } \\
\text { para encontrar a tranquilidade } \\
\text { e paz de espírito. Sem o auxílio } \\
\text { da espiritualidade, o caminho a } \\
\text { transcorrer até a finitude pode } \\
\text { tornar-se mais difícil, árduo e } \\
\text { penoso }\end{array}$ \\
\hline
\end{tabular}

processo saúde-doença ${ }^{26}$. Uma pesquisa, realizada em 2013, também evidenciou resultados semelhantes, com concepçóes positivas sobre a influência da espiritualidade e religiosidade para a vitalidade, com efeitos negativos em menor proporção ${ }^{27}$.

Relacionada à qualidade de vida, outros estudos trouxeram aspectos particulares. Uma pesquisa quantitativa detectou que a religiosidade está ligada à espiritualidade, saúde, bem-estar e felicidade ${ }^{26}$, assim como já observado em outros estudos ${ }^{28-30}$. Uma revisão de literatura, feita em 2018, constatou que a espiritualidade, além de interferir na qualidade de vida, auxilia na redução da depressão, da falta de esperança e da ansiedade geradas pelo câncer ${ }^{31}$, o que vai ao encontro de outro estudo, de 2014, que demonstrou que a prece é uma estratégia eficiente para reduzir a ansiedade em pacientes oncológicos ${ }^{32}$.

Um estudo transversal latino-americano, realizado em 2017, correlacionou maiores escores de Coping espiritual-religioso a uma melhor percepção da qualidade de vida ${ }^{15}$, assim como já constatado em outra pesquisa, feita em $2010^{33}$. Para alguns autores, Coping é concebido como o conjunto de estratégias, cognitivas e comportamentais, utilizadas pelos indivíduos com o objetivo de manejar situaçôes estressantes ${ }^{34-36}$.

As atividades e crenças religiosas também foram interligadas à melhor saúde e à qualidade de vida ${ }^{30}$ e à 
redução do impacto da dor, fadiga ou percepção de ameaça à vida, durante o tratamento do câncer ${ }^{37}$.

Ademais, foi constatado, em Botucatu, no ano de 2009, que a prática religiosa vivenciada pelos pacientes constitui uma estratégia que legitima e ameniza a incerteza diante das questóes de caráter moral, pessoal e social, relativas à condiçâoo oncológica crônica ${ }^{38}$. Por isso, estudos concluem que a espiritualidade e a religiosidade contribuem para uma melhora da saúde e do bem-estar geral $^{30,39}$. Esses resultados, em concordância, reforçam a relevância de uma pesquisa integral do sujeito que aborde a qualidade de vida do paciente oncológico ${ }^{33}$.

A espiritualidade e o bem-estar espiritual têm provado um efeito positivo em pacientes com câncer, como um importante componente de saúde e contentamento ${ }^{28}$. Existem também outras influências benéficas da espiritualidade e religiosidade, as quais envolvem o conforto e a esperança que auxiliam na aceitação da doença em crianças, adolescentes ${ }^{40}$ e adultos ${ }^{21}$.

Um estudo americano, realizado em 2018, mostra que, apesar dos aspectos positivos, também pode haver malefícios. A espiritualidade pode aumentar o impacto negativo da ameaça à vida percebida pelos pacientes ${ }^{37}$ e pode estar associada à incidência de efeitos colaterais, sofrimento psicológico, ansiedade e depressão ${ }^{14}$.

Outra pesquisa demonstra que a espiritualidade e a religiosidade contribuem para a compreensão do câncer ${ }^{19}$. Um estudo exploratório relatou que isso é possível especialmente a partir de rituais religiosos e do apoio da comunidade, e geram esperança para enfrentar as dificuldades ${ }^{17}$. Além disso, estudos mostram que elas podem contribuir para a adesáo ao tratamento do câncer ${ }^{14}$ e serem uma estratégia de lidar com o câncer, desde o diagnóstico até em cuidados paliativos oncológicos ${ }^{15}$.

Em uma pesquisa transversal feita com indivíduos sobre quimioterapia, os pacientes citaram o apego a um ser superior e disseram que a fé em Deus é o que dá condições de enfrentamento da doenç ${ }^{11}$. Em concordância, um estudo qualitativo descritivo mostra que pessoas religiosas creem na proteção divina e a reconhecem como sustento e conforto frente ao adoecimento ${ }^{22}$. Outro autor adiciona que as crenças são formas de transferir a responsabilidade do câncer para Deus ou um "Ser Supremo", e tornar a doença algo suportável ${ }^{25}$. Além disso, uma pesquisa exploratória descritiva notificou que a busca espiritual é uma forma de encontrar tranquilidade e paz de espírito, a fim de tornar a história natural da doença algo menos difícil, árduo e penoso ${ }^{41}$.

Outro estudo vê a espiritualidade de uma forma um pouco diferente e constata que o paciente oncológico a busca com a finalidade de minimizar o sofrimento ou obter maior esperança de cura com o tratamento ${ }^{21}$. Uma pesquisa acrescenta que isso é possível porque a espiritualidade pode proporcionar uma ressignificação da doença para o sujeito, fazendo-o encará-la de outra forma. O sujeito passa a ter novas metas e desafios a cumprir e a espiritualidade oferece o suporte necessário para encarar essa etapa ${ }^{13}$.

Outrossim, foi observado que a maioria dos participantes entrevistados utilizou a religiosidade como fonte de apoio no enfrentamento do câncer ${ }^{8,16}$. A religiosidade, quando bem incorporada na vida do paciente, o ajuda com as consequências que o câncer trará para seu dia a dia e influenciará essencialmente a sua vida e o seu modo de viver durante o tratamento ${ }^{8}$.

Entrevistas relataram o significado positivo do apoio espiritual, pois a fé proporciona uma maneira de pensar construtiva $^{12}$. A espiritualidade pode gerar um novo sentido à morte dos pacientes oncológicos ${ }^{18} \mathrm{e}$ uma ressignificância da vida dos pacientes adolescentes ${ }^{17} \mathrm{e}$ até dos adultos ${ }^{39}$. Esses achados vão ao encontro de uma pesquisa transversal que relata que indivíduos com câncer, em sofrimento espiritual, vivem um estado de tristeza relacionado à falta de significância à vida ${ }^{42}$.

Outro estudo relaciona a religiosidade e a espiritualidade aos profissionais de saúde. O cuidado espiritual de pacientes com câncer coloca o doente e até a enfermeira oncológica no caminho para o desenvolvimento espiritual, que ajuda na promoção do conforto, da sensação de paz e da satisfação interior, que auxiliam no tratamento da doença ${ }^{43}$. Esse processo de cuidado deve ser planejado para fornecer necessidades e práticas espirituais entre os cuidadores e os familiares de pacientes com câncer ${ }^{44}$.

Um estudo mostra que as questôes relacionadas à espiritualidade influenciam nas decisões médicas e na forma como o paciente viverá a experiência da doença ${ }^{20,45}$. Exemplo disso é o reconhecimento da dimensão espiritual na avaliação adequada da dor total, importantíssimo para o controle do sintoma, já que o estado espiritual do paciente pode ter influência direta na percepção da dor como sofrimento ${ }^{45}$.

Muitos pacientes buscam ajuda da espiritualidade para aceitar e lidar com o câncer, por isso, a equipe médica deve levar em consideração o cuidado espiritual em pacientes oncológicos ${ }^{46}$. Outra pesquisa traz também o aspecto da enfermagem e mostra que, assim como os médicos, os profissionais de enfermagem devem considerar a espiritualidade dos pacientes, já que ela fornece informaçóes para o plano de cuidados e assistência integral ao indivíduo, e é uma estratégia de ação necessária para lidar com o sofrimento infantil e familiar de pacientes com câncer ${ }^{47}$. Em convergência, foi constatado que a maioria dos pacientes gostaria que seus médicos abordassem sobre sua religiosidade e espiritualidade e sentiriam mais empatia e confiança no médico que questionasse esses temas ${ }^{30}$. 
Também em relação ao cuidado com os pacientes oncológicos, uma pesquisa observacional, realizada no Sul do Brasil, constatou que essas pessoas necessitam compartilhar ideias e experiências vivenciadas com o câncer, por isso, é importante que realizem a Terapia Espiritual, um cuidado terapêutico complementar que considera o biopsicossocial do indivíduo e a sua autonomia perante a doença ${ }^{48}$. Além disso, a terapia possibilita unir mente e corpo, a fim de ter melhores resultados no tratamento oncológico ${ }^{49}$.

Outra área relacionada é a oncologia integrativa, um ramo da medicina integrativa que associa o cuidado convencional com novas práticas multidisciplinares no cuidado do câncer, como a uniáo mente e corpo, e que pode estimular a efetividade e reduzir os sintomas adversos da doença ${ }^{50}$. Além disso, terapias com animais e com a comunidade, nas quais cáes, gatos, entre outros, participam de visitas a hospitais públicos e privados e casas de repouso ${ }^{51}$; terapia cognitivo-comportamental, que auxilia o paciente a interpretar seus sentimentos e moldá-los ${ }^{52}$; e os cuidados paliativos, que buscam melhorar a qualidade de vida do doente e mantê-lo o mais ativo possível, têm mostrado resultados positivos no tratamento do câncer.

\section{CONCLUSÃO}

$\mathrm{O}$ apego à espiritualidade e à religiosidade influencia positivamente na saúde biopsicossocial do paciente com câncer: pode melhorar a qualidade de vida, o bem-estar e a vitalidade, e contribui na redução do estresse, do impacto da dor, da fadiga ou da percepçáo de ameaça à vida. Ademais, pacientes dotados de espiritualidade e religiosidade podem apresentar maior aceitação do câncer do tratamento, além de maior esperança e positividade no decorrer da doença.

\section{CONTRIBUIÇÕES}

Todos os autores contribuíram substancialmente na concepção e/ou no planejamento do estudo; na obtenção, na análise e/ou interpretação dos dados; assim como na redação e/ou revisão crítica; e aprovaram a versão final a ser publicada.

\section{DECLARAÇÃO DE CONFLITO DE INTERESSES}

Nada a declarar.

\section{FONTES DE FINANCIAMENTO}

Não há.

\section{REFERÊNCIAS}

1. Michaelis H, Vasconcelos CM. Michaelis dicionário escolar língua portuguesa. São Paulo: Melhoramentos; 2016.

2. Peres MFP, Arantes ACLQ, Lessa PS, et al. A importância da integração da espiritualidade e da religiosidade no manejo da dor e dos cuidados paliativos. Rev Psiq Clín. 2007;34(Suppl 1):82-7. doi: http://dx.doi.org/10.1590/ S0101-60832007000700011

3. Matos HCJ. Curso de espiritualidade cristá para leigos. Vol. I. Belo Horizonte: O Lutador; 1996.

4. Instituto Nacional de Câncer José Alencar Gomes da Silva [Internet]. Rio de Janeiro: INCA; c1996. O que é câncer? [2019] [acesso 2019 fev 22]. Disponível em: http://www1.inca.gov.br/conteudo_view.asp?id=322

5. Farinhas GV, Wendling MI, Dellazzana-Zanon LL. Impacto psicológico do diagnóstico de câncer na família: um estudo de caso a partir da percepçáo do cuidador. Pensando Fam. 2013;17(2):111-129.

6. Canassa I, Ferret JCF. A influência da espiritualidade/ religiosidade na saúde mental de pacientes oncológicos: uma revisão bibliográfica. Rev UNINGÁ Review. 2016;28(2):67-71.

7. Souza VCT, Pessini L, Hossne WS. Bioética, religião, espiritualidade e a arte do cuidar na relação médicopaciente. Rev Bioethikos. 2012;6(2):181-190.

8. Crescenti M. Brasil é $2^{\circ}$ pais mais religiosos do mundo, diz pesquisa. BBC Brasil.com [Internet]. 2007 dez 19 [acesso 2019 jan 25]. Disponível em: https://www.bbc. com/portuguese/reporterbbc/story/2007/12/071218_ religiaocrescenti.shtml

9. Gifford W, Thomas O, Thomas R, et al. Spirituality in cancer survivorship with First Nations people in Canada. Support Care Cancer. 2019 Aug;27(8):2969-2976. doi: https://doi.org/10.1007/s00520-018-4609-z

10. Balboni MJ, Puchalski CM, Peteet JR. The relationship between medicine, spirituality and religion: three models for integration. J Relig Health. 2014 Oct;53(5):1586-98. doi: https://doi.org/10.1007/s10943-014-9901-8

11. Oliveira DS, Furtado LNS, Azevedo FB, et al. Influência da espiritualidade, religiosidade e crenças pessoais na qualidade de vida de pacientes em quimioterapia. Temas em saúde. 2018;18(2):76-102.

12. Freire MEM, Vasconcelos MF, Silva TN, et al. Assistência espiritual e religiosa a pacientes com câncer no contexto hospitalar. Rev Fund Care Online. 2017;9(2):356362. doi: http://dx.doi.org/10.9789/2175-5361.rpcfo. v9.4906

13. Sousa Junior PTX, Teixeira SMO, Cardoso J, et al. A importância da espiritualidade no tratamento de pacientes oncológicos. In: Anais da Mostra de Pesquisa em Ciência e Tecnologia 2017; Fortaleza: DeVry Brasil, Damásio, Ibmec; 2017 jul 4. 
14. Sousa FFPRD, Freitas SMFM, Farias AGS, et al. Religious/spiritual coping by people with cancer undergoing chemotherapy: integrative literature review. SMAD, Rev Eletrônica Saúde Mental Álcool Drog. 2017;13(1):45-51. doi: http://dx.doi.org/10.11606/ issn.1806-6976.v13i1p45-51

15. Matos TDS, Meneguin S, Ferreira MLS, et al. Quality of life and religious-spiritual coping in palliative cancer care patients. Rev Latino-Am Enfermagem. 2017;25:e2910. doi: https://doi.org/10.1590/1518-8345.1857.2910

16. Nejat N, Whitehead L, Crowe M. The use of spirituality and religiosity in coping with colorectal cancer. Contemp Nurse. 2017;53(1):48-59. doi: https://doi.org/10.1080/ 10376178.2016.1276401

17. Souza VM, Frizzo HCF, Paiva MHP, et al. Spirituality, religion and personal beliefs of adolescents with cancer. Rev Bras Enferm. 2015;68(5):791-6. doi: https://doi. org/10.1590/0034-7167.2015680504i

18. Miranda SL, Lanna MAL, Felippe WC. Espiritualidade, depressão e qualidade de vida no enfrentamento do câncer: estudo exploratório. Psicol Cienc Prof. 2015;35(3):870-85. doi: https://doi.org/10.1590/19823703002342013 .

19. Mesquita AC, Chaves ECL, Avelino CCV, et al. A utilização do enfrentamento religioso/espiritual por pacientes com câncer em tratamento quimioterápico. Rev Latino-Am Enfermagem. 2013;21(2):[7telas]. doi: https://doi.org/10.1590/S0104-11692013000200010

20. Espinha DCM, Lima RAG. Dimensão espiritual de crianças e adolescentes com câncer: revisão integrativa. Acta Paul Enferm. 2012;25(N. Esp.):161-5. doi: http:// dx.doi.org/10.1590/S0103-21002012000800025

21. Guerrero GP, Zago MMF, Sawada NO, et al. Relação entre espiritualidade e câncer: perspectiva do paciente. Rev Bras Enferm. 2011;64(1):53-9. doi: https://doi. org/10.1590/S0034-71672011000100008

22. Espíndula JA, Do Valle ERM, Bello AA. Religião e espiritualidade: um olhar de profissionais de saúde. Rev Latino-Am Enferm. 2010;18(6):[8telas]. doi: https://doi. org/10.1590/S0104-11692010000600025

23. Fornazari SA, Ferreira RER. Religiosidade/espiritualidade em pacientes oncológicos: qualidade de vida e saúde. Psic Teor e Pesq. 2010;26(2):265-72. doi: https://doi. org/10.1590/S0102-37722010000200008.

24. Alcorn SR, Balboni MJ, Prigerson HG, et al. "If God wanted me yesterday, I wouldn't be here today": religious and spiritual themes in patients' experiences of advanced cancer. J Palliat Med. 2010;13(5):581-8. doi: https://doi. org/10.1089/jpm.2009.0343

25. Sampaio AD, Siqueira HCH. Influência da espiritualidade no tratamento do usuário oncológico: olhar da enfermagem. Ensaios Cien, Cien Biol Agra Saúde. 2016;20(3):151-8. doi: https://doi.org/10.17921/14156938.2016v20n3p153-160
26. Meneguin S, Matos TDS, Ferreira MLSM. Perception of cancer patients in palliative care about quality of life. Rev Bras Enferm. 2018;71(4):2114-20. doi: https://doi. org/10.1590/0034-7167-2017-0360

27. Gobatto CA, Araújo TCCF. Religiosidade e espiritualidade em oncologia: concepçóes de profissionais da saúde. Psicologia USP. 2013;24(1):11-34. doi: https://doi. org/10.1590/S0103-65642013000100002

28. Puchalski CM, Sbrana A, Ferrell B, et al. Interprofessional spiritual care in oncology: a literature review. ESMO Open. 2019;4(1):e000465. doi: https://doi.org/10.1136/ esmoopen-2018-000465

29. Jim HS, Pustejovsky JE, Park CL, et al. Religion, spirituality, and physical health in cancer patients: a metaanalysis. Cancer. 2015;121(21):3760-8. doi: https://doi. org/10.1002/cncr.29353

30. Lucchetti G, Granero AL, Bassi RM, et al. Spirituality in clinical practice: what should the general practitioner know?. Rev Bras Clin Med. 2010;8(2):154-8.

31. Xing L, Guo X, Bai L, et al. Are spiritual interventions beneficial to patients with cancer?: a meta-analysis of randomized controlled trials following PRISMA. Medicine (Baltimore). 2018;97(35):e11948. doi: https:// doi.org/10.1097/MD.0000000000011948

32. Carvalho CC, Chaves ECL, Iunes DH, et al. A efetividade da prece na redução da ansiedade em pacientes com câncer. Rev Esc Enferm USP 2014;48(4):683-9. doi: https://doi.org/10.1590/S0080-623420140000400016

33. Pinto C, Ribeiro JL. Avaliação da espiritualidade dos sobreviventes de cancro: implicaçôes na qualidade de vida. Rev Port Sau Pub. 2010;28(1):49-56.

34. Antoniazzi AS, Dell'Aglio DD, Bandeira DR. O conceito de coping: uma revisão teórica. Estud Psicol.1998;3(2):273-94. doi: http://dx.doi.org/10.1590/ S1413-294X1998000200006

35. Lazarus RS, Folkman S. Stress, appraisal, and coping. New York: Springer Publishing Company; 1984.

36. Straub RO. Psicologia da saúde: uma abordagem biopsicossocial. 3 ed. Porto Alegre: Artmed; 2005.

37. Visser A, de Jager Meezenbroek EC, Garssen B. Does spirituality reduce the impact of somatic symptoms on distress in cancer patients? Cross-sectional and longitudinal findings. Soc Sci Med. 2018 Oct;214:57-66. doi: https://doi.org/10.1016/j.socscimed.2018.08.012

38. Spadacio C, Barros NF. Terapêuticas convencionais e não convencionais no tratamento do câncer: os sentidos das práticas religiosas. Interface (Botucatu). 2009;13(30):45-52. doi: https://doi.org/10.1590/ S1414-32832009000300005

39. Benites AC, Neme CMB, Santos MA. Significados da espiritualidade para pacientes com câncer em cuidados paliativos. Estud Psicol. 2017;34(2):269-279. doi: https://doi.org/10.1590/1982-02752017000200008 
40. Nascimento LC, Oliveira FCS, Moreno MF, et al. Cuidado espiritual: componente essencial da prática da enfermeira pediátrica na oncologia. Acta Paul Enferm. 2010;23(3):437-40. doi: http://dx.doi.org/10.1590/ S0103-21002010000300021.

41. Tarouco RL, Muniz RM, Guimaraes SRL, et al. Spirituality and living with cancer in the process of dying. Rev Enferm UFPE on line. 2009;3(4):102126. doi: https://doi.org/10.5205/reuol.581-3802-1RV.0304200929

42. Caldeira S, Timmins F, de Carvalho EC, et al. Clinical validation of the nursing diagnosis spiritual distress in cancer patients undergoing chemotherapy. Int J Nurs Knowl. 2017;28(1):44-52. doi: https://doi. org/10.1111/2047-3095.12105

43. Moosavi S, Rohani C, Borhani F, et al. Consequences of spiritual care for cancer patients and oncology nurses: a qualitative study. Asia Pac J Oncol Nurs. 2019;6(2):13744. doi: https://doi.org/10.4103/apjon.apjon_37_18

44. Kiyancicek Z, Caydam OD. Spırıtual needs and practıces among family caregivers of patients with cancer. Acta Paul Enferm. 2017;30(6):628-34. doi: http://dx.doi. org/10.1590/1982-0194201700090

45. Silva JO, Araújo VMC, Cardoso BGM, et al. Dimensão espiritual no controle da dor e sofrimento do paciente com câncer avançado. Relato de caso. Rev Dor. 2015;16(1):71-4. doi: https://doi.org/10.5935/18060013.20150014

46. Hatamipour K, Rassouli M, Yaghmaie F, et al. Spiritual needs of cancer patients: a qualitative study. Indian J Palliat Care. 2015;21(1):61-7. doi: https://doi. org/10.4103/0973-1075.150190

47. Silva TP, Leite JL, Stinson J, et al. Estratégias de ação e interaçáo para o cuidado à criança hospitalizada com dor oncológica crônica. Texto Contexto Enferm. 2018;27(4):e3990017. doi: http://dx.doi. org/10.1590/0104-07072018003990017

48. Aureliano WA. Terapias espirituais e complementares no tratamento do câncer: a experiência de pacientes oncológicos em Florianópolis (SC). Cad Saúde Colet. 2013;21(1):18-24. doi: http://dx.doi.org/10.1590/ S1414-462X2013000100004

49. Rose IS. Espiritualidade, terapia e cura: um estudo sobre a expressão da experiência no santo daime [dissertação]. Florianópolis (SC): Universidade Federal de Santa Catarina, Centro de Ciências Humanas, Programa de Pós-Graduação em Antropologia Social; 2005.

50. Siegel P, Barros NF. O que é a oncologia integrativa? Cad Saúde Colet. 2013;21(3):348-54. doi: https://doi. org/10.1590/S1414-462X2013000300018

51. Rede Câncer. No Alvo: pesquisa clínica em câncer caminha para terapias cada vez mais individualizadas [Internet]. Rio de Janeiro: INCA. 2010 nov 12 [acesso 2019 jan 25]. Disponível em: https://bvsms.saude.gov. br/bvs/periodicos/rede_cancer_12.pdf
52. Santana JJRA, Zanin CR, Maniglia JV. Pacientes com câncer: enfrentamento, rede social e apoio social. Paidéia. 2008;18(40):371-84. doi: http://dx.doi.org/10.1590/ S0103-863X2008000200013

Recebido em 22/8/2019 Aprovado em 20/4/2020 